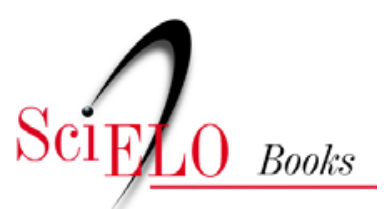

\title{
Prisões e globalização
}

\author{
António Pedro Dores
}

\section{SciELO Books / SciELO Livros / SciELO Libros}

DORES, A.P. Prisões e globalização. In: COELHO, M.T.Á.D., and CARVALHO FILHO, M.J., orgs. Prisões numa abordagem interdisciplinar [online]. Salvador: EDUFBA, 2012, pp. 31-52. ISBN 97885-232-1735-8. Available from: doi: 10.7476/9788523217358.004. Also available in ePUB from: http://books.scielo.org/id/7mkg8/epub/coelho-9788523217358.epub.

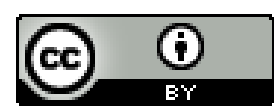

All the contents of this work, except where otherwise noted, is licensed under a Creative Commons Attribution $\underline{4.0 \text { International license. }}$

Todo o conteúdo deste trabalho, exceto quando houver ressalva, é publicado sob a licença Creative Commons Atribição 4.0.

Todo el contenido de esta obra, excepto donde se indique lo contrario, está bajo licencia de la licencia Creative Commons Reconocimento 4.0. 


\section{Prisões e globalização}

António Pedro Dores

\section{Introdução}

Para alguns autores a globalização é um processo que começou há meio milénio, com os Descobrimentos. Para outros ele é bem mais recente, já que sem a industrialização e a colonização que a suportou, faz pouco mais de duzentos anos, não haveria a possibilidade de aceleração de trocas que permite actualmente as economias de todo o mundo concorrerem em tempo real e à distância. Mais em tempos mais próximos de nós, a revolução dos transportes, o caminho-de-ferro, as estradas para automóveis e a aviação civil, bem como a revolução informática, ou a organização de mercados financeiros, primeiro nacionais e depois globais, infraestruturaram aquilo que é a globalização actual, que também passa pela mediatização de uma agenda global e pela concorrência em tempo real das actividades profissionais mais qualificadas, como nas áreas da consultoria, da ciência e tecnologia, da saúde, do ensino superior, para não falar do crime organizado. A globalização manifesta-se em fenómenos como a Internet, a expansão do inglês e do dólar (eventualmente do euro) como língua e moeda francas, mas também nos efeitos globais do efeito de estufa, das mudanças climáticas, da exclusão social - incluindo destruição de modos de vida tradicionais, as migrações, as fomes, as sedes - ou da guerra por petróleo.

As lutas da era da globalização opõem os neo-liberais, apostados na liderança do governo federal norte-americano, detentor de meios de coerção inigualáveis para evitar formas de regulação que não sejam do seu interesse, aos que preferem desenvolver políticas multilaterais. Observando esta oposição do ponto de vista da análise do que possa 
influir nos sistemas prisionais, é sabido como os EUA admitem a pena de morte como pena regularmente aplicada por vários Estados e como nos últimos anos se tornou um debate político a legalização da tortura (que de facto avançou nas instâncias legislativas federais norte-americanas) como forma de extrair confissões a presumidos terroristas, amigos de terroristas ou pessoas que de alguma forma possam ter vivido (saibam disso ou não) alguma situação cuja descrição possa ser útil aos caça-terroristas. A ambas as tendências, cuja persistência e desenvolvimento se organizam em doutrina judicial alternativa àquela que é reconhecida actualmente no ocidente, se opôs explicitamente a ONU, ainda que de maneira precária e incapaz de impedir o avanço da onda securitária lançada, sobretudo, a partir dos atentados de 11 de Setembro de 2001 nos EUA.

A proposta doutrinária liderada actualmente pelo governo federal norte-americano implica retornar, do ponto de vista jurídico, à sociedade de ordens, em que as pessoas, consoante o respectivo estilo de vida e estatuto social (por exemplo, se são nacionais norte-americanos ou não, se têm fenótipo africano ou espânico ou do médio oriente ou outro que seja considerado exótico) têm acesso a diferentes sistemas jurídicos. Na avaliação de Jakobs e Meliá (2003): um sistema para julgar crimes económicos, ditos de colarinho branco, em que as penas de prisão tendem a cair em desuso; outro para julgar os crimes de trabalhadores, que pagam com prisão os seus crimes; um terceiro sistema concebido para julgar terroristas, em que os direitos de defesa, tal como os conhecemos actualmente, deixam de estar garantidos, até porque à partida, para entrarem no subsistema judicial nessa condição, é porque o princípio da presunção de inocência já foi invertido. Guantanamo e as prisões secretas espalhadas pelo mundo pelo governo federal norte-americano para escapar à jurisdição do poder judicial do seu país são consequências práticas da aplicação de tais políticas, em contradição com a doutrina oficial do sistema judicial vigente.

Neste cenário, é possível manter a neutralidade? Sim, é a resposta.

A União Europeia, por exemplo, reage lentamente e arrasta os pés à cumplicidade denunciada por Collin Powel, ex-secretário de Estado de George W. Bush, a respeito das prisões secretas que aceitou no seu próprio território. Ao mesmo tempo que não se coíbe, por seu turno, de organizar, com países do norte de África, sistemas de controlo das 
ondas de imigração que alimentam os mercados de mão-de-obra barata do Sul da Europa, incluindo o uso da força arbitrária. ${ }^{1}$

Os opositores da guerra no Iraque, denunciadores das torturas em Abu Grahib, tantas vezes considerados anti-americanos pelos que defendem políticas securitárias, hesitam perante, ou simplesmente não notam, o facto de tais torturas serem também praticadas nas prisões em território dos EUA, (PERKINSON, 2004; BUTTERFIELD, 2004). Da mesma forma que as práticas de tortura condenadas pela ONU em Espanha são ignoradas pelas autoridades democráticas do país vizinho de Portugal, que tomaram o poder contra a guerra no Iraque. ${ }^{2}$

Quanto mais perto da órbita de responsabilidade própria de cada um, mais se torna repugnante, embaraçoso e difícil reconhecer (para não falar em combater) as práticas de abuso de autoridade, em especial a das autoridades de segurança que, implicitamente, nos aparecem tanto mais directamente ameaçadores quanto mais arbitrários sejam os seus comportamentos conhecidos.

Esta experiência, a que chamamos segredo social, fenómeno social vulgar que obscurece na consciência de cada ser humano as percepções que respeitam a realidades quotidianas imorais, ameaçadoras, terríveis, merece uma identificação e explicações mais detalhadas, para o que contribuiremos mais adiante. Insistimos, para já, na ideia de que a abordagem a temas prisionais feita sem a consciência de estes serem sintomáticos do decurso de lutas sociais de grande profundidade emocional, histórica e civilizacional, se reduz, com prejuízo de sentido, às políticas e vidas prisionais em sentido estrito. O saber como se vive em e como funcionam as prisões depende da capacidade que se tenha de perspectivar teoricamente o que passa no interior dessas instituições, em função do sentido geral da vida em sociedade.

Pode parecer muito abstracta ou ideológica esta última declaração. Mas a verdade muito prática é só uma: com tantos entraves para observar o que se passa nas prisões, instituição onde todos parecem ter excelentes razões para esconder tudo, não é o olhar - por muito experimentado e sagaz que possa ser - do cientista social que vai con-

1 Em Marrocos, no final de 2006, um grupo de candidatos a imigrantes foi abandonado à sua sorte no deserto pelas autoridades do país, apoiadas e instigadas por um convénio que troca dinheiro europeu pela colaboração na redução do número de imigrantes africanos, incluindo métodos ilegais e letais.

2 Para informações sobre a situação da tortura em Espanha ver < http://www.nodo50.org/tortura/ $\operatorname{spip} />$. 
seguir descortinar o essencial, muitas vezes inclusivamente o básico. Caso a sociedade, ela própria, não produza os meios técnicos de observação das instituições e das vidas prisionais, por exemplo, através do acolhimento e tratamento sistemática das denúncias, nomeadamente em instituições independentes e empenhadas na prevenção contra a tortura, a ciência por si só não terá a capacidade de estabelecer postos de observação descomprometidos com as próprias condições institucionais de encarceramento e, portanto, com as tendências securitárias actualmente dominantes em todo o mundo. Mas a ciência pode distanciar-se - como aconselham os mestres - e utilizar os dados empíricos de forma a reconstruir, na imaginação e nos conhecimentos fundamentais sobre a natureza humana, aquilo que pode ser descoberto pelos métodos científicos.

Mesmo se as tendências sociais dominantes fossem de desencarceramento, como eram por ocasião dos anos sessenta e setenta, quando as ideias abolicionistas das penas de prisão pareciam realizáveis através da institucionalização das penas alternativas à prisão, a ideia comum sobre as prisões era (como ainda é actualmente) de que todas as prisões são iguais umas às outras e sempre assim foram e serão. É mérito da ciência, e em particular de Michel Foucault (1999) e mais recentemente de (CUNHA, 2002), mostrar que a história das prisões modernas é muito recente e atribulada, ao contrário do senso comum.

A ideia estereotipada e estilizada das prisões é um fenómeno global que acompanha (e explica?) a difusão e adopção da ideia de sistema penal, como uma forma de dar uma imagem de racionalidade higienista da justiça e da moral social, capaz de reduzir à anormalidade, à criminalidade, à marginalidade, ao outro menorizado, muitas das causas dos problemas e dissidências sociais. Tal efeito (ao mesmo tempo psicológico, social e político) resiste e persiste porque - ao contrário do que acontecia anteriormente, quando as penas eram executadas como espectáculos públicos - o sistema penitenciário permite reforçar a repugnância social pelos criminosos (e pelos carcereiros) com o segredo social, isto é, o compromisso profissional e social, técnico e político, jornalístico e científico, de imaginar (mais do que observar) os (melhores) funcionamentos institucionais e as (melhores) vidas na prisão. Por exemplo, embora toda a gente saiba que as prisões se tornaram, nas últimas décadas, os supermercados de drogas mais lucrativos - o que é 
também um fenómeno global decorrente das políticas proibicionistas, doutrinariamente sediadas na ONU, como acontece com as políticas de prevenção contra a tortura - continua a imaginar-se que os muros da prisão são um sistema de segurança impenetrável. De outra maneira não seria possível continuar a pensar como racional a estratégia de perseguição policial para conter os vícios privados, até porque os factos mostram, à evidência, os efeitos perversos de tal política. ${ }^{3} \mathrm{O}$ que acontece, porém, é que a ideia intencionalmente simplista do que sejam as prisões, possibilitada pelos segredos sociais que se organizam em torno da justiça, das polícias, do Estado e das acções repressivas, e imposta pela lógica intimidatória própria da política de monopólio da violência legítima por parte das instituições do Estado, por vezes confundida ou misturada com o efeito de persuasão e prevenção criminal que só a autoridade do Estado tem capacidade para desenvolver, tal ideia simplista das prisões, dizia, funciona (simbólica e ideologicamente) como uma espécie tampa de ralo sem a qual todo o sistema político e judicial ameaça desmoronar-se. Sem a possibilidade de obrigar a penar os arguidos, os magistrados teriam de aprender a manifestar o seu poder de outros modos, quem sabe como fazem os professores - através de juízos de valor aplicados em escalas de zero a vinte. Para o que precisariam de outro tipo de autoridade do que aquela a que hoje em dia dispõem.

As resistências à observação das prisões são, portanto emocionais, históricas e civilizacionais, antes de serem políticas e científicas. Estão profundamente enraizadas na humanidade de cada leitor e de cada investigador e mexem com os sentimentos de segurança de cada um. Para exemplificar o que se quer dizer, experimente-se organizar uma palestra sobre a sociedade sem prisões. Logo aparecerão curiosos incrédulos a perguntar: o que fazer com os criminosos? Ou mobilize-se a experiência de participação no fórum social mundial (FSM). Questione-se como são tratadas as questões prisionais no meio da cacofonia que procura meios de organizar uma globalização alternativa. $\mathrm{O}$ facto é que não são tratadas, a não ser marginalmente, como fenómenos locais e exóticos, as questões prisionais. O autor destas linhas teve oportunidade de perguntar, num seminário sobre criminalização dos pobres, em Porto Alegre, Janeiro de 2002, se num "outro mundo possível" as prisões poderiam ser abolidas. A resposta, aparentemente consensual na mesa

3 Sobre o tema vale a pena ler Michael Woodiwiss (1988, 2005) e Klahr (2006). 
sul-americana, foi surpreendente: "Sem prisões, onde passariam a viver, uma vez mudado o regime político, os que nos fazem viver clandestinos com receio de sermos presos e torturados?" (citado de cor e em versão livre). Pelo tratamento da mesma questão, membros de uma associação de direitos humanos andaluza interessada em questões prisionais procuraram, e também o que encontraram, em Nairobi, Janeiro de 2007, onde se reuniu o FSM, foram referências sem centralidade doutrinária, filosófica, política, analítica. ${ }^{4}$ Todavia, há movimentos que avançam no combate de fundo da preservação e aprofundamento dos princípios doutrinários da igualdade perante a lei e do respeito pelo Estado de Direito, cujas principais realizações podem ser observadas nas prisões, como se fossem laboratórios sociais. ${ }^{5}$ Em particular, os movimentos globais de prevenção contra a tortura, mobilizados em torno do Protocolo Adicional à Convenção contra a Tortura e outros Tratamentos ou Penas Cruéis, Desumanas ou Degradantes, que entrou em vigor porque foi subscrito e ratificado por vinte países - em meados de 2006. Tal protocolo prevê a necessidade de intensificação e alargamento da organização de prevenção de práticas ilícitas, divulgando localmente a experiência das inspecções internacionais que a ONU já praticava anteriormente, mas de forma esporádica e rara, dada a escassez de meios para intervir em todo o mundo e, também, as limitações de conhecimento que os peritos independentes que trabalharam nessas funções tinham sobre as especificidades locais, isto é, o desconhecimento das queixas e alegações, bem assim como os meios de encobrimento ou de protecção dos perpetradores das ilegalidades a prevenir. A partir da entrada em vigor do Protocolo Adicional espera-se que a mobilização de pessoas e organizações contra a tortura as possa colocar, com apoio político do Estado mas sem a sua interferência directa, como prevê o tratado livremente subscrito pelos Estados signatários, em posição de intervir de forma mais institucionalizada e sistemática, com o máximo de conhecimento de causa, conforme as melhores práticas entretanto desenvolvidas na ONU, no sentido de abolir as práticas de tortura.

4 A luta contra o neo-liberalismo económico pode obstruir a luta pelo liberalismo judicial, doutrinariamente igualitário, e constituir assim um segredo social suplementar, de natureza ideológica, para os activistas da alter-globalização, a somar ao segredo social que já recobre os temas judiciários em geral.

5 É costume dizer-se que as prisões estão para as sociedades como as drogas e o jogo estão para as pessoas: revelam-lhes os atributos de carácter mais profundos ou, o que é o mesmo dito de outra forma, os atributos que estão sujeitos a regimes de segredo social, de estratégias de encobrimento social. 
Tais avanços poderão explicar a necessidade do governo federal norte-americano de legalizar certas formas de tortura já anteriormente praticadas (não apenas nos EUA), impedindo desse modo, ou pelo menos dificultando antecipadamente, eventuais denúncias de desrespeito pela lei por parte dos Estados e abrindo mais campo a práticas de encobrimento, com base na alargada ambiguidade legal.

\section{Crescimento global do número de prisioneiros}

Nove e um quarto milhões de pessoas viviam na prisão em 2005, em todo o mundo, contra oito milhões em $1999 .{ }^{6}$ Alguns países, entre os quais o Brasil, viram crescer muito o número de prisioneiros nos últimos anos. Os EUA são os campeões do encarceramento, com 2,19 milhões de prisioneiros, seguidos da China e da Rússia, com 1,55 e 0,87 milhões respectivamente. Estes números são por um lado impressionantes pelo seu volume - é como se o mundo tivesse reservado um canto do tamanho de Portugal (que conta com 10 milhões de habitantes) para fazer aí o seu inferno - mas provavelmente conservadores, já que existe uma competição mundial para evitar contas altas. Nos EUA, por exemplo, os presos sob a tutela do executivo, em Guantanamo, nas prisões secretas dentro e fora do território, não são contabilizados. A notícia do relatório britânico que cita os números referidos acima menciona que para as informações chinesas apenas são contados os condenados e os que estão em detenção administrativa. Presume-se que faltarão nessas contas outras pessoas igualmente sem liberdade por decisão do Estado, eventualmente em campos de educação.

Note-se, isso é relevante, que os números, e principalmente a sua explicação e interpretação mais detalhada, colocam problemas emocionais importantes. Caso o leitor não goste das políticas dos EUA ou do próprio povo norte-americano, é-lhe fácil de interpretar o facto de haver tantos presos (seja pela incapacidade de orientarem as suas vidas e a sociedade em geral, seja pelo reconhecimento nestes números dos prazeres mórbidos e perversos que tal povo alegadamente alimentará). Para defesa dos EUA haverá outros argumentos, como seja o facto de a generalidade dos detidos (perto de metade) serem negros, o que pode

6 Segundo estimativas divulgadas por Walmslay (2010). 
remeter para o passado, para África, e definitivamente para o carácter dos condenados, a explicação de tais números. Na China, onde não há negros em quantidade suficiente, se se disser que há tortura e brutalidades em massa nas prisões, que nas próprias fábricas os trabalhadores não são respeitados e os direitos humanos de todos não são defendidos, e só raramente alegados, a tendência para dar crédito, ou pelo menos dar de barato, que isso possa estar a acontecer na China é sensivelmente maior do que se se tratasse de um país ocidental. Quanto mais próximo de nós, mais difícil é reconhecer (apesar das notícias) o que possa estar a acontecer, apesar da disponibilidade da informação ser, evidentemente, maior.

As informações sobre os sistemas prisionais no mundo são problemáticas porque são recolhidas com métodos diferentes, de acordo com os respectivos critérios judiciais e criminais em vigor, os critérios estatísticos em uso, os interesses políticos de cada Estado e a respectiva capacidade de interferência, maior ou menor, na divulgação dos trabalhos estatísticos. São problemáticas porque mexem de perto com as nossas emoções humanas mais fundamentais, de sobrevivência, de solidariedade, de submissão e cooperação, de legitimação do uso da violência, vinculadas de modo intenso com as identidades nacionais e de classe de cada um e com os fundamentos do Estado num sentido pouco racional, como é aquele a que se fez menção anteriormente. É a própria crença na racionalidade judicial e penal, sem cuja legitimidade as instituições fundamentais do Estado moderno se podem tornar ou serem sentidas (o que é o mesmo) como periclitantes que está em causa, para os responsáveis judiciais e políticos mas também - e sobretudo para as cidadãos. A defesa do estado das prisões é, no seu sentido mais radical, a defesa do Estado, incluindo a defesa do estado de coisas e dos sentimentos de segurança tanto mais necessários e desejados quanto pairem sentimentos sociais de insegurança.

Para o jornal on line About, a população prisional norte americana é de 1,5 milhão de pessoas. ${ }^{7}$ Para a Human Rights Watch a população prisional norte-americana é de 2,3 milhões. ${ }^{8}$ Provavelmente ambos os números estão certos, pois contarão populações diferentes, embora sob a mesma designação. Mas as diferenças nos resultados não são negli-

7 <http://crime.about.com/od/prison/a/blbjs041107.htm >. GERARD, 2005)

$8<$ http://www.hrw.org/news/2006/11/30/us-addiction-incarceration-puts-23-million-prison> (FELLNER,2006) 
genciáveis. Cada qual, consoante a tese que pretenda ilustrar, prefere utilizar as referências mais convenientes, seja à maximização do efeito contabilístico - por se entender deverem ser contadas todas as situações de restrições de liberdade, independentemente dos regimes serem mais fechados (como as celas brancas de que praticamente não se sai, mantido sem referências de modo a provocar perturbações mentais) ou mais abertos (com permissão para trabalhar e estudar fora do recinto prisional) - seja à sua minimização - por se entender que em certas condições de detenção não há castigo mas antes um serviço de reabilitação, desígnio que acompanhou sempre as intenções declaradas nas reformas penitenciárias. O trabalho com estatísticas, especialmente no caso das prisões, é emocionalmente tão carregado que mesmo quando se tratam números tão gerais como os referenciados as diferenças podem ser estas.

Se acontece no EUA, também pode acontecer com todas as estatísticas de outros os países. Ainda assim é possível contabilizar os volumes relativos de encarceramento em diversos países do mundo e saber que o Japão (embora esteja a viver um período de forte incremento do número de presos, na sequência da crise política e social estrutural que tem vivido na última década e meia) e os países nórdicos na Europa são onde o uso das prisões é tradicionalmente menor.

Quadro 1- População prisional por 100,000 habitantes ${ }^{9}$

\begin{tabular}{|c|c|c|c|c|c|c|c|c|c|c|c|}
\hline 霡 & $\begin{array}{l}\text { 줄. } \\
\text { D. } \\
\text { D. }\end{array}$ & $\stackrel{ }{\nwarrow}$ & 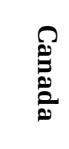 & 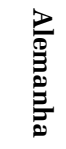 & 馬 & 承 & 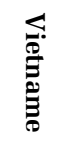 & 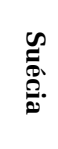 & 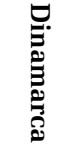 & 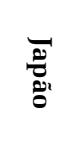 & 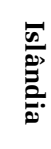 \\
\hline 740 & 713 & 124 & 102 & 98 & 92 & 80 & 75 & 64 & 61 & 37 & 29 \\
\hline
\end{tabular}

Fonte: (WIKIPEDIA, 2007)

Merece referência especial o caso da Finlândia, anteriormente na órbita política da União Soviética - tradicionalmente com taxas de encarceramento das mais altas do mundo -, que na sequência da implosão do império soviético transitou voluntariamente para a esfera de influência da União Europeia, tendo-se tornado um exemplo de estudo de sociedade da informação, Castels (2004), e, ao mesmo tempo, adoptou os padrões

$9<$ http://en.wikipedia.org/wiki/Prison\#Prisons_by_country >. (WIKIPEDIA, 2007) 
jurídicos e penais dos países nórdicos quando passou a seguir os seus padrões culturais e políticos. O autor catalão faz notar que a sociedade da informação e dos computadores, de que os EUA são o zénite, não é obrigatoriamente uma sociedade penal - como acontece na América do Norte. Na Finlândia, recém-chegada aos lugares de topo dos desempenhos informáticos industriais, prova que é possível seguir modelos de desenvolvimento bem sucedidos sem encarceramento em massa.

Voltando ao quadro 1, os números apresentados, apesar do louvor que merece o trabalho da sua compilação, têm significados que só podem ser interpretados com a observação e conhecimento das realidades locais, completados não apenas por outros números (séries estatísticas) mas também pelas filosofias políticas adoptadas em cada caso, e em especial no que toca às políticas prisionais, bem como as tendências mais recentes de evolução da situação de segurança objectiva e subjectiva. Por exemplo, o caso português, que na viragem do século era o sistema prisional com maior taxa de encarceramento da União Europeia, com mais de 140 presos por 100 mil habitantes, num 40 país com baixa taxa de criminalidade relativa oficialmente apurada, está em situação de decréscimo de população prisional (que rondará, em 2006, 120 presos por 100 mil habitantes) em contra ciclo com a Espanha, a Grã-Bretanha (em crescimento do número de presos no mesmo período, países que tomaram o lugar cimeiro na EU a Portugal) e com a França, que, apesar de não ser dos países da União Europeia com maior taxa de encarceramento, vive a circunstância de uma fase de politização da questão prisional, que é tema das campanhas eleitorais de praticamente todos os candidatos presidenciais. Em Portugal o tema da reforma prisional saiu das campanhas eleitorais em 2005, depois de estar sempre presente desde o início do século.

Estudos quantitativos sobre a relação homens/mulheres, jovens/ adultos/idosos, presos preventivos/presos condenados, primários (com uma só condenação), reincidentes (no mesmo crime, mais de uma vez condenados), presos não nacionais, número de doentes crónicos e mentais, número de utilizadores de drogas, número de presos em celas unipessoais, e em celas sem casa-de-banho, sobrelotação das cadeias, e outros, permitem produzir dados de qualidade variável. Que todavia são reunidos por pessoas como Pierre Tournier, que deles são capazes de extrair ensinamentos úteis à organização de políticas públicas, ao 
combate aos preconceitos, ao debate político elevado sobre temas tão emocionantes e profundos como as prisões.

Há, todavia, dois tópicos que são mais politicamente sensíveis que outros. Os custos das prisões (que aqui não trataremos) e o obituário prisional. Nestes campos, a ponderação entre o respeito pelo segredo social, os valores económicos e a vida humana complica-se. Em qualquer parte do mundo, um prisioneiro ferido - por efeito de torturas, de lutas ou auto-flagelação - não merece a atenção pública e política que merece um cadáver que saído da prisão.

Para quem trabalha nas prisões, quem observa as consequências práticas na vida das pessoas e as dificuldades/impossibilidades de tornear os bloqueios que degradam a humanidade dos prisioneiros (e também os guardas e funcionários), o sofrimento em vida pode fazer parecer a morte uma solução desejável. Isso mesmo se testemunhou na situação de extrema fragilidade da condição de um toxicodependente moribundo que foi deixado na sua cela, em Lisboa, durante 4 ou 5 dias sem comer - o que é contra os regulamentos - até que o desenlace ocorreu, na presença acompanhante do companheiro de cela: "Ele queria morrer" - disse um elemento do pessoal de saúde. Só não foi um escândalo público porque apenas a família pode servir legalmente de interlocutora das autoridades nestas ocasióes. Ora o pai estava preso, a mãe, muito pobre e doente, incapaz de suportar qualquer tipo de pressão mediática que seria necessária para tornar conhecido o caso. Do caso fica a lição: do que se passou antes da morte (incluindo a degradação física de um toxicodependente, como outros, que partiu um estilete que serviu de seringa artesanal numa das coxas) a oportunidade de denúncia depende do próprio, da sua capacidade de fazer circular informação e de persistir na queixa quando questionado - em reclusão - sobre isso mesmo. Na morte, a denúncia depende do conhecimento que se tenha das circunstâncias em que aconteceu e da vontade e capacidade de luta da família.

É por isso que a greve de fome é, dentro da prisão, uma arma muito requisitada pelos presos para lutarem pelo que entendem necessitar. E com efeitos práticos. Pois a má publicidade é um risco permanente a ser gerida com todo o cuidado pelas administrações penitenciárias e pelos governos. O carácter extremamente emocional dos contextos sociais de encarceramento (seja no interior, seja no exterior) produz efeitos 
historicamente conhecidos, que transformam as crises prisionais, desde que haja mortos, em notícia e comentário político. Um dos maiores temores das administrações penitenciárias, e dos governos, é a capacidade de mediatização que possam ter os eventos prisionais, que estão fechados entre muros precisamente para evitar ao máximo que isso aconteça. Porém, não são os muros que evitam que, de quando em vez, os casos prisionais se tornem casos públicos, seja a propósito de histórias fantásticas, inimagináveis noutras instituições, seja sob a forma dramática de motins e desordens recorrentes, aproveitando, perversamente, a quem disso souber tirar proveito, sejam presos ou guardas, direcção da cadeia ou traficantes, políticos ou oposição, media ou académicos estudiosos.

Quadro 2 - Taxas de mortalidade nas prisões de alguns países do Conselho da Europa

\begin{tabular}{|c|c|c|c|}
\hline $\begin{array}{l}\text { mortes por } 10000 \\
\text { prisioneiros }\end{array}$ & 1997 & 2001 & 2003 \\
\hline Portugal $^{10}$ & 106 & 79 & -- \\
\hline Rússia & 78 & 59 & -- \\
\hline Moldávia & 65 & 82 & 74 \\
\hline Letónia & 59 & 12 & 38 \\
\hline Bélgica & 59 & 36 & -- \\
\hline Dinamarca & 56 & 43 & 53 \\
\hline Bulgária & 46 & 35 & 44 \\
\hline Finlândia & 40 & 45 & 29 \\
\hline França & 37 & 49 & 40 \\
\hline Escócia & 32 & 33 & 23 \\
\hline Espanha & $31^{*}$ & 31 & 32 \\
\hline Grécia & $20^{*}$ & 40 & -- \\
\hline Itália & $30^{*}$ & 32 & 27 \\
\hline Hungria & $34^{*}$ & 237 & 29 \\
\hline Ucrânia & $74^{*}$ & 272 & 49 \\
\hline
\end{tabular}

Fonte: Deaths in penal institutions (SPACE 1, 2010) * dados do ano 2000

10 Quadro 3 Taxas de mortalidade nas prisões portuguesas, por 10 mil presos

\begin{tabular}{|l|l|l|l|l|l|}
\hline & $1997^{*}$ & $2000^{* *}$ & $2004^{* * *}$ & $2005^{* * *}$ & $2006^{* * * *}$ \\
\hline Portugal & 106 & 60 & 64 & 72 & 70 \\
\hline
\end{tabular}

*Fonte: Deaths in penal institutions (1997), Council of Europe

**Fonte: Conselho da Europa, Space 2001.12

*** Fonte: dados brutos da DGSP de 84 e 94 mortos respectivamente em 2004 e 2005, no fim do ano.

****Fonte: estimativa para o ano de 2006 com base na resposta Ministério da Justiça a requerimento do grupo parlamentar Os Verdes referente aos 6 primeiros meses do ano (45 mortos). 
Chocam mais as mortes que acontecem a pessoas jovens e antes de serem condenadas. ${ }^{11} \mathrm{O}$ que mostra que o contacto com as autoridades penais pode ser letal. Por se saber disso, de maneira oficial, digamos assim, é que os países signatários da Convenção da ONU contra a tortura declaram o seu respeito pela doutrina dos Direitos Humanos, manifestando formal e solenemente o seu acordo de princípio às práticas de prevenção da tortura, embora nem sempre a colaboração política e administrativa no local às equipes de inspecção seja exemplar. ${ }^{12}$ Esta ambiguidade política entre os desejos e as realidades (bem mais violentas e perversas do que o que estamos geralmente preparados para aceitar, seja por razões psicológicas seja por razões políticas) está na origem de escolhas ambíguas do pessoal nacional para representar os Estados signatários nas instâncias de administração das práticas preventivas. $^{13}$

Nos casos de mortes, há regularmente explicações pouco plausíveis para o sucedido que chegam à opinião pública: falta de informação qualificada e precisa sobre o que terá acontecido, incluindo disputas judiciais para apurar a verdade. Não é que o mesmo não se passe em litígios na prisão a que não estejam associados cadáveres. O que explica a diferença entre os males de que resultam mortes nas prisões e os outros, é que os primeiros são mais difíceis de esconder, na sua quietude, pois não admitem intimidações nem estigmas. Não podem ser apresentados - ainda que isso seja tentado por vezes - como perigosos para a sociedade. E os cadáveres, na sua radicalidade, podem ser contados de um modo irrecusável, ao contrário dos conflitos, por exemplo. A boa vontade com que tais contagens são feitas pode ser

11 Por exemplo: "Morto depois de menos de um dia na prisão", (JEAVANS, 2006), cf. < http:// news.bbc.co.uk/1/hi/uk/4814928.stm>. Em subtítulo escreve: "No último ano 78 homens, mulheres e jovens mataram-se na prisão em Inglaterra e Gales. Metade esperava julgamento ou decisão judicial.”. No caso, a notícia referia-se ao suicídio de um jovem de 24 anos.

12 Para uma apreciação diplomática do comportamento dos Estados perante este tipo de problemas, a nível global, ver websites das organizações globais para a prevenção da tortura, como seja a Associação para a Prevenção da Tortura <http://www.apt.ch/> ou a Organização Mundial Contra a Tortura < http://www.omct.org/>.

13 A escolha portuguesa de um antigo e controverso antigo director geral dos serviços prisionais para o comité de prevenção da tortura do Conselho da Europa ou a indigitação do governo espanhol de um antigo procurador geral envolvido na guerra suja contra a organização armada basca ETA para representar o país na nova estrutura de administração do Protocolo Adicional da Convenção contra a tortura da ONU são apenas dois exemplos mais próximos e que são do nosso conhecimento. 
percebida pela ausência de explicações sobre os números de obituário prisional e sobre as respectivas variações, que podem ser enormes, tanto entre países como de um ano para o outro no mesmo país, quadro 2.

Pode ser que as condições de detenção, sempre a braços com custos elevados, não permitam socorro de pessoal de saúde em situações de emergência; ou que a prioridade às questões de segurança também não facilitem a ajuda de presos em caso de necessidade, principalmente quando a pressão é grande sobre os serviços; nomeadamente quando há situações crónicas de sobrelotação, de falta de pessoal, que acontece frequentemente na actual conjuntura histórica dados os crescimentos sustentados dos números de presos e as limitações orçamentais globais para despesas sociais.

Não se pode dizer que não seja do conhecimento público o essencial do que se passa nas prisões. A questão é a de saber se é possível e interessa ao público, na sua relação cívica e política com o Estado, tomar conhecimento prático, assumir responsabilidades colectivas, face a realidades conhecidas e publicadas? Ou é preferível delegar nos órgãos próprios do Estado a responsabilidade de lidar directamente e por conta própria com as realidades que as sociedades, assim, podem meter debaixo do tapete, como se usa dizer? ${ }^{14}$

Serão, estas mortes, riscos a assumir em nome da necessidade de fazer justiça? Ou, um dia, passar-se-á a sentir como repulsiva a possibilidade de, dadas as circunstâncias em que tudo acontece, fora do quadro de vigilância regular em que decorre a vida colectiva, as prisões poderem ser palco, ainda que episódico e esporádico, de justiça feita pelas próprias mãos, praticada impunemente, com a cumplicidade objectiva de quem não promove a sistemática investigação, descoberta e publicitação dos factos apurados?

Não se pode generalizar, naturalmente. Mas não é possível que penas de morte extra-judiciais possam ser encomendadas para serem executadas dentro da prisão? Onde as vítimas não podem fugir ou defender-se. Esta hipótese colocada, num programa de opinião televisivo em Portugal, que tratava do suicídio nas prisões, gerou telefonemas emocionados de pessoas que disseram ter vivido e testemunhado o terror da

14 A resposta cabal a estas perguntas retóricas podem ser observadas pelos historiadores, quando revisitam as revoluções e podem questionar-se sobre o lugar e o sentido - pelo menos simbolicamente centrais - das libertações dos presos das cadeias, pelo menos desde a tomada da Bastilha. 
ameaças de morte a coberto das paredes prisionais, nomeadamente sob a forma de execução de terceiros. Estas situações serão raras e extremas? Provavelmente sim. Não estão é quantificadas. Nem explicadas. E, por isso, não se pode saber mais do que cada caso isolado que organizações denunciantes e órgãos de comunicação social, casuisticamente, e por vezes politicamente intimidados, fazem chegar à opinião pública, com efeitos imprevisíveis: a indiferença ou o escândalo, consoante a agenda mediática e o espírito popular na ocasião. ${ }^{15}$ Mas a capacidade de instigar o terror, coberto pelo segredo social, de o inscrever em estigmas auto-incorporados como se fossem segredos de Estado, com a cumplicidade tácita das populações, incluindo (ou principalmente?) aquelas estatisticamente mais vítimas de criminalização, torna a ideia comum de dissuasão do crime e uso legítimo da força do Estado contra o crime outra coisa do que aquela noção doutrinal e moralmente firme que geralmente se tem de reacção moral organizada da sociedade, através das instâncias institucionais próprias, aos comportamentos anti-sociais individualizados ou de pequenos grupos. De facto, toda a sociedade, todas as sociedades, cada um de nós, está, de uma forma ou de outra, necessariamente envolvido com um processo social muito complexo que é (mal) conhecido sob a designação de reforma penitenciária, umas vezes como actor de encobrimentos (cada um a seu nível), outras vezes como vítimas (geralmente apenas da cumplicidade indesejada ou da ignorância das perversidades que utilizam os meios prisionais para suas próprias finalidades particulares, mas por vezes como vítimas da violência directa, vitaliciamente traumatizante)

\section{O mundo e as prisões}

O sequestro é das práticas mais antigas da humanidade. Remete-nos para a própria possibilidade de reprodução biológica das sociedades humanas. O rapto de mulheres é uma actividade tão antiga que acontece ainda hoje estar ritualizado, em certas civilizações e classes sociais, como indispensável exercício romântico ante-nupcial. Remete-

15 Por exemplo, no Ocidente, nas festividades natalícias há falta de notícias, os controlos políticos da comunicação social estão menos organizados no terreno, por efeito das férias, e há melhor acolhimento popular a apelos públicos à compaixão. É boa altura para vingarem denúncias de casos de prisão. 
-nos também para as profundezas dos mistérios das sociabilidades em geral. Também a síndrome dos reféns, que os torna recorrentemente admiradores dos seus raptores e das suas perspectivas de luta, e aos observadores externos admirados com a reacção ao mesmo tempo tão regular e tão incompreensível dos sequestrados, revela-nos a nossa ignorância sobre o que sejam os laços de identificação social que produzem tais efeitos. Estes factos bem estabelecidos e conhecidos são contra-intuitivos porque a teoria social, ela própria, se deixa envolver por teias de preconceitos erróneos sobre a natureza humana. Todavia toma como certos e universais os preconceitos, em vez dos factos recorrentes, preferindo tornar excepção ou anormal aquilo que poderia revelar erros conceptuais de que não está disposta a abdicar. A teoria social participa, essa é a tese aqui defendida, e, portanto, reforça os segredos sociais que fundam o status quo sobre as políticas de violência, a que a sociologia se refere misteriosamente, parafraseando Max Weber, como o monopólio da violência legítima.

Observando qualquer sistema prisional, facilmente se comprovará haver uma aplicação significativamente diferenciada das penas de prisão consoante o sexo. E acontece de tal modo que ninguém se lembra de reclamar contra a discriminação que isso possa eventualmente representar. É para todos evidente que as penas de prisão são aplicadas mais aos homens que às mulheres. Mas ninguém explica racional e convincentemente tal evidência, de tão evidente. Porquê?

Outro fenómeno do mesmo género obscurece o processo de estigmatização, observado classicamente por Erwin Goffman. O estigma original era visível: na face ou nas mãos dos condenados, a quem eram subtraídos falanges, orelhas, narizes e outras partes do corpo, de modo a que todos os que com eles se encontrassem ficassem cientes de que se tratava de uma pessoa com tendências criminosos específicas. Nas sociedades modernas o estigma não é visível. É incorporado frequentemente pelo próprio acusado ou condenado, cuja tendência psicológica se auto-identificar com o perfil penalmente idealizado do tipo de criminoso capaz de concretizar as práticas de que tem de se defender, se for capaz. O estigma social não é apenas uma etiqueta: é também uma busca interior de quem seja socialmente condenado à procura de simpatia pela imagem social de si mesmo, tal e qual ela é produzida - tão intensamente - pelo próprio sistema judicial. Procura essa que o 
pode levar a procurar confirmar, em sociedade, a identidade que lhe é penalmente atribuída, mimando na prática o tipo-ideal definido pelas ciências criminais que lhe foram aplicadas. ${ }^{16}$

Numa prisão os presos - condenados ou não - parecem e comportam-se como criminosos, do mesmo modo que os sequestrados podem ser condicionados a mimar, uma vez libertados, os seus sequestradores. Isso mesmo nos deixou dito Foucault quando escreveu que os sistemas prisionais são indispensáveis à produção dos criminosos, tornando erudito o dito popular que considera a prisão universidade do crime. $\mathrm{O}$ mais extraordinário das prisões é que é possível, senão frequente, que as mesmas pessoas que entendem intuitivamente, e reproduzem de bom grado, frases populares deste tipo, sejam capazes de, eventualmente na mesma troca de palavras, comparar as penitenciárias a hotéis de cinco estrelas, a sorte dos desvalidos "pensionistas do Estado" a regimes liberais de cama, mesa e roupa lavada. Como se queixam as polícias e as magistraturas, a volubilidade da opinião pública a respeito de casos judiciais é imprevisível: tanto se reclama a libertação de presos como penas duras para quem não há provas acusatórias, consoante as ondas emocionais que se formam em sociedade.

Semelhantemente, também as teorias sociais se confundem perante os factos evidentes e não dão sinais de frustração por serem incapazes de produzir uma explicação, ainda que fosse controversa, sobre a discriminação sexual na aplicação de penas de prisão ou sobre a auto-reprodução dos estigmas sociais pelas suas próprias vítimas ou sobre a polarização das posições sociais face a certos casos de justiça por contraste ao alheamento mais vulgar. Ao contrário. Os investigadores sociais dão-se conta de (e resignam-se a) a necessidade de se identificarem, eles próprios, ora com as instâncias condenatórias e estigmatizantes ora com os/as criminalizados/as estigmatizados/as, importando eles próprios a polarização própria do campo em observação,

16 Este mecanismo de sociabilidade, o mimetismo de práticas de outros e de imagens socialmente difundidas, é vulgar, nas famílias, nos empregos, nos partidos políticos. Eventualmente não são tidos em suficiente conta nas nossas representações dominantes, a ter em consideração a surpresa com que os resultados de uma experiência como aquela que foi desenvolvida em Stanford foram recebidos pelos seus organizadores ( http://www.prisonexp.org/). Os estudantes divididos em reclusos e guardas cumpriram de tal maneira as suas obrigações que o fim da experiência foi antecipado, para evitar consequências negativas para os participantes, de tal maneira envolvidos com os respectivos papeis que a depressão e a violência ameaçavam tornarem-se crónicas. 
tornando-se difícil o convívio académico e a troca de argumentos entre pessoas relacionadas com o assunto em causa (CHRISTIE, 2000). ${ }^{17}$

\section{Segredos e naturezas sociais}

Em todos os países de mundo, virtualmente, existem os respectivos sistemas prisionais tutelados pela lei local. A ponto de se poder imaginar - sem razão - que todas as sociedades humanas se servem de prisões como forma de punição. Foucault causou admiração quando, no seu clássico Vigiar e Punir, fixou para as ciências sociais a ideia de que a prisão moderna, as penitenciárias que começaram a ser construídas no final do século XIX, eram resultado de um projecto técnico utilitaristas estudado e proposto por Bentham, sob a designação de Panopticon. Mas o mundo das prisões, nem por isso - apesar dos estudos históricos e antropológicos que confirmam a sua rápida evolução estrutural, tanto ao nível do direito (MORRIS; ROTHMAN, 1998) como das práticas sociais. (CUNHA, 2002) - deixou de ser representado, erradamente, como um mundo imutável e à parte da sociedade. Como um mundo tabu, uma espécie de inferno, uma inversão perversa do ideal de sociedade: violência quotidiana internalizada à força, sem recursos institucionais para instâncias de mediação judicial. As prisões são a experiência real, contingente, do fetiche negativo do ideal de sociedade a que aderimos à força. À força do Estado, actor autorizado para o exercício monopolista da força legítima, como explicou Max Weber. À força da sociedade, que deposita as suas esperanças na vida em família, apoiada pelos diversos serviços sociais (escola, sistema de saúde, polícia) e económicos (empregos, subsídios e seguros para enfrentar dificuldades extremas), para desfrutar das promessas da modernidade, como a liberdade, a igualdade, a mobilidade, as férias, a informação, o entretenimento.

Quando as coisas não correm de feição para a sociedade, ou para o Estado, é previsível que se sinta a necessidade de organizar a resistência (social e política) para evitar ir atrás de mudanças impostas

17 Este autor refere que, para a Noruega, uma das actividades chave para ser possível a redução da aplicação das penas de prisão e a opção por regimes abertos que caracterizam o actual sistema norueguês foi a imersão, uma vez por ano, que reunia, durante um longo fim-de-semana, magistrados e guardas prisionais, polícias e familiares de presos, advogados e jornalistas, políticos e presidiários, académicos e directores de cadeia, médicos e gestores, bem como todos os grupos interessados em assuntos prisionais. 
por eventos singulares ou atitudes minoritárias ou externas. Tal como provavelmente desde sempre aconteceu aos humanos. Modernamente, há que encontrar formas de produzir explicações (históricas, políticas, sociais) que confirmem à sociedade e ao Estado que ambos, ou pelo menos este último, por delegação, estão/está em controlo da situação e capaz de continuar a garantir estabilidade e segurança susceptíveis de suportarem a credibilidade dos exercícios de planeamento no quadro de uma divisão de trabalho que transfere as recompensas para o futuro, no tempo da distribuição, posterior ao da produção.

Trata-se de um correlato social do mesmo fenómeno que transforma o sequestrado num simpatizante da causa do sequestrador, o condenado em mimo do tipo de criminoso que lhe é descrito pelos magistrados, a criança simulacro dos seus pais, o discípulo uma réplica do mestre. Em situações de maior tensão, a tendência dos seres humanos em assumirem para si a convicção de adesão emocional ao paradigma simbólico dominante - o espírito de submissão - parece extremar-se e exigir formas expressivas desse compromisso. Desse modo se maximizam socialmente as hipóteses de sucesso dos empreendimentos em que todos, superiores e subordinados, estão desigualmente envolvidos.

Para quem esteja de fora, descomprometido com as trocas emocionais em curso, pode parecer estranho, desumano, irracional. Aquilo que parece estranho ao observador externo é naturalizado por quem viva por dentro, solidariamente, as relações sociais em análise. Se assim é, não será que tal tendência também afecta o observador, incrédulo quando se coloca de fora das relações sociais, mas menos capaz de analisar o que se passa nas redes sociais de que se sente parte integrante?

Na guerra, na transição para a vida adulta, a propósito de uma aliança social entre famílias ou clãs, sempre que muda de estação do ano, todos os povos organizam rituais regidos por mitos de controlo sobre a natureza e as próprias sociedades, a que chamamos religião, que exigem e exibem a violência ritualizada, simbólica e corporal, eventualmente a guerra. Esta violência legítima, que procura controlar outros tipos de violência, é uma violência mágica, como a dança da chuva ou a guerra que se justifica em nome de tornar mais difícil a violência em sociedade (ou a tortura para descobrir a verdade). Nos outros povos e culturas as violências parecem-nos repugnantes. Mas dentro dos nossos contextos existências quotidianos nem pensamos 
na violência que está envolvida: tome-se o caso das touradas, que impressionam os amigos dos animais e que deixam os aficionados estarrecidos de incompreensão pela falta de respeito alheia pela expressão pública e popular da nobreza dos toiros. Ou tome-se o caso dos alimentos, como os porcos ou as cobras ou os macacos ou as formigas voadoras ou os cães, face ao que as diferentes culturas produzem saberes, gostos e repugnâncias que se incorporam socialmente em cada indivíduo. Tome-se o exemplo das guerras, das fomes, das lutas às epidemias. Vê-las na televisão traz-nos inconscientemente à consciência a pergunta desresponsabilizadora: não serão as vítimas culpadas do que lhes aconteceu, por que não se preveniram o suficiente? O pudor que alguns de nós sentimos e que nos faz reprimir, pela razão, estas inquietações, noutras pessoas não existe. Há mesmo quem elabore sobre a xenofobia natural, organizando o racismo. Tal falta de pudor pode mesmo ser levada ao extremo, em certas circunstâncias, de serem seres humanos a utilizarem as dificuldades alheias para explorar quem sejam as vítimas - por exemplo, tomando para si ajuda humanitária 50 para terceiros ou organizando limpezas étnicas e genocídios. Sim, também na Europa e recentemente tais casos se deram.

Não é humanamente possível viver com a responsabilidade de cuidar solidariamente dos desvalidos. Em toda a parte do mundo, mas especialmente nas cidades, as pessoas obrigam-se a delimitar mais ou menos as suas disponibilidades de actuar em solidariedade perante a urgência de vidas em competição entre si. Não é possível distribuir por todos os pobres alguma esmola sem nos acontecer como a S. Francisco de Assis. Portanto, comedimo-nos. E - este é o nosso ponto - não prestamos atenção. Não temos a capacidade - provavelmente ainda bem - de prestar atenção a não ser a um conjunto bem limitado de questões e problemas sobre os quais nos dispomos a agir intencionalmente: as questões profissionais e familiares, a gestão de alguns amigos e dos tempos livres e pouco mais. Ainda assim os especialistas sempre nos recordam que estamos a esquecer de organizar melhor o tempo de trabalho, a comunicação com a família, a inteligência emocional com os amigos, as férias com melhor relação preço-qualidade, etc.

A verdade é que os segredos sociais são-nos tão indispensáveis como os hábitos sociais. Sem eles não seria possível concentrarmos as nossas atenções e intenções em objectivos limitados mas consequentes, 
com repercussões sociais a que os sociólogos chamam agências. Os segredos sociais estão para as estruturas sociais como a matéria invisível recentemente descoberta como sendo o esqueleto do universo está para o cosmos. A violência humana está para os Estados como a vida quotidiana está para as instituições, como a existência está para aquilo que é reconhecido e imaginado como realidade ou como a natureza está para as suas expressões acessíveis à nossa volúvel (má?) consciência.

\section{Referências}

BUTTERFIELD, Fox. Mistreatment of Prisoners Is Called Routine in U.S, NY TIMES, 8 maio 2004.

CASTELS, Manuel. A Galáxia Internet - Reflexões sobre a internet, negócios e sociedade. Lisboa: FCG, 2004.

CHRISTIE, Nils. Crime Control as Industry - Towards Gulags, Western Style. 3. Ed.. London: Routledge: Routledge, 2000.

CUNHA, Manuela Ivone. Entre o bairro e a prisão: tráficos e trajectos, Fim de Século, 2002.

FELLNER, Jamie. US Addiction to Incarceration Puts 2.3 Million in Prison. Human Rights Watch, dec. 2007. Disponível em: <http://www.hrw.org/ news/2006/11/30/us-addiction-incarceration-puts-23-million-prison>. Acesso em: 14 fev. 2007.

FOUCAULT, Michel. Vigiar e punir - História da violência nas prisões. 20. ed. Petrópolis: Vozes, 1999.

GERARD, Vanessa. U.S. Prison Population Approaches 1.5 Million. Corrections Today, v. 67, n. 1 feb. 2005. Disponível em: < http://crime. about.com/od/prison/a/blbjs041107.htm>. Acesso em: 14 fev. 2007. JAKOBS, Günther; MELIÁ, Manuel Cancio. Derecho Penal del Enemigo. Madrid: Cuadernos Civitas, 2003.

JEAVANS, Christine. Dead after less than a day in prison. BBC News, 6 abr. 2006. Disponível em: <http://news.bbc.co.uk/1/hi/uk/4814928.stm> Acesso em: 3 ago. 2010.

KLAHR, Marco Lara. Hoy te toca la muerte, México: Planeta, 2006.

MORRIS, Norval, e David J. Rothman.The Oxford History of the Prison The Practice of Punishment in Western Society, Oxford: Oxford University Press, 1998. 
PERKINSON, Robert. Some US prisons as bad as Abu Ghraib [mensagem pessoal] Mensagem recebida por < perk@hawaii.edu> em 21 jul. 2006.

SPACE 1 - COUNCIL OF EUROPE ANNUAL PENAL STATISTICS. Deaths in penal institutions, 2010. Disponível em: <http://www3.unil.ch/wpmu/ space/space-i/>. Acesso em: 3 ago. 2010

WALMSLAY, Roy (Ed.). World Prison Population List. Disponível em:

<http://aic.gov.au/stats/other/wpl.html>, Acesso em: 3 ago. 2010.

WIKIPEDIA, THE FREE ENCYCLOPEDIA. Disponível em: <http:// en.wikipedia.org/wiki/Prison\#Prisons_by_country >. Acesso em: $14 \mathrm{fev}$. 2007.

WOODIWISS, Michael. Gangster Capitalism: The United States and the Global Rise of Organized Crime. Londres: Constable, 2005.

WOODIWISS, Michael. Crime, Crusades and Corruption - Prohibitions in the United States, 1900-1987, London: Piter Publisher, 1988. 